\title{
Processing of Alnico Permanent Magnets by Advanced Directional
}

\section{Solidification Methods}

Zou, Min ${ }^{1}$; Johnson, Francis ${ }^{1}$; Zhang, Wanming ${ }^{1}$; Zhao, Qi ${ }^{1}$; Rutkowski, Stephen F. ${ }^{1}$;

Zhou, Lin ${ }^{2,3}$; Kramer, Matthew J. ${ }^{2,3}$

${ }^{1}$ Ceramic and Metallurgy Technologies, General Electric Global Research, Niskayuna, NY, United States

${ }^{2}$ Ames Laboratory, Ames, IA, United States

${ }^{3}$ Iowa State University, Ames, IA, United States

\section{Abstract}

Advanced directional solidification methods have been used to produce large ( $>15 \mathrm{~cm}$ length) castings of Alnico permanent magnets with highly oriented columnar microstructures. In combination with subsequent thermomagnetic and draw thermal treatment, this method was used to enable the high coercivity, highTitanium Alnico composition of $39 \% \mathrm{Co}, 29.5 \% \mathrm{Fe}, 14 \% \mathrm{Ni}, 7.5 \% \mathrm{Ti}, 7 \% \mathrm{Al}, 3 \% \mathrm{Cu}$ (weight $\%$ ) to have an intrinsic coercivity $\left(\mathrm{H}_{\mathrm{ci}}\right)$ of $2.0 \mathrm{kOe}$, a remanence $\left(\mathrm{B}_{\mathrm{r}}\right)$ of $10.2 \mathrm{kG}$, and an energy product $(\mathrm{BH})_{\max }$ of 10.9 MGOe. These properties compare favorably to typical properties for the commercial Alnico 9. Directional solidification of higher Ti compositions yielded anisotropic columnar grained microstructures if high heat extraction rates through the mold surface of at least $200 \mathrm{~kW} / \mathrm{m}^{2}$ were attained. This was achieved through the use of a thin walled ( $5 \mathrm{~mm}$ thick) high thermal conductivity $\mathrm{SiC}$ shell mold extracted from a molten $\mathrm{Sn}$ bath at a withdrawal rate of at least $200 \mathrm{~mm} /$ hour. However, higher Ti compositions did not result in further increases in magnet performance. Images of the microstructures collected by scanning electron microscopy (SEM) reveal a majority $\alpha$ phase with inclusions of secondary $\alpha_{\gamma}$ phase. Transmission electron microscopy (TEM) reveals that the $\alpha$ phase has a spinodally decomposed microstructure of FeCo-rich needles in a NiAl-rich matrix. In the $7.5 \%$ Ti composition the diameter distribution of the FeCo needles was bimodal 
with the majority having diameters of approximately $50 \mathrm{~nm}$ with a small fraction having diameters of approximately $10 \mathrm{~nm}$. The needles formed a mosaic pattern and were elongated along one $\langle 001\rangle$ crystal direction (parallel to the field used during magnetic annealing). $\mathrm{Cu}$ precipitates were observed between the needles. Regions of abnormal spinodal morphology appeared to correlate with secondary phase precipitates. The presence of these abnormalities did not prevent the material from displaying superior magnetic properties in the $7.5 \% \mathrm{Ti}$ composition. Higher $\mathrm{Ti}$ compositions did not display the preferred spinodal microstructure, explaining their inferior magnetic properties.

Keywords: Alnico; directional solidification; permanent magnets; transmission electron microscopy. 


\section{INTRODUCTION}

Alnico permanent magnets have attracted revived interest since the recent spike in rare earth element prices. [1]-[5]. Stoner-Wohlfarth theory predicts a maximum energy product $(\mathrm{BH})_{\max }$ of 49 MGOe for a 67 vol.\% packed $\mathrm{Fe}_{65} \mathrm{Co}_{35}$ nanostructure, given the $\mathrm{FeCo}$ nanowires do not exceed the coherence radius of the

order of $10 \mathrm{~nm}$ [6]. The highest energy products achieved in Alnico permanent magnets, however, are 13.4 and 9.0 MGOe, in laboratory and commercial grades Alnico 9, respectively, with an intrinsic coercivity $\left(\mathrm{H}_{\mathrm{ci}}\right)$ of $1.5 \mathrm{kOe}$ [7]. The highest $\mathrm{H}_{\mathrm{ci}}$ in commercial Alnico is $2.2 \mathrm{kOe}$ in Alnico $8 \mathrm{H}$ with an energy product of 5.0 MGOe [8]. The major difference between the Alnico $8 \mathrm{H}$ and 9 compositions is that $8 \mathrm{H}$ has higher Co and $\mathrm{Ti}$ contents. It has been reported that high $\mathrm{Ti}$ content favors the high coercivity but impedes the formation of the columnar grain structure, thus degrading the remanence $\left(\mathrm{B}_{\mathrm{r}}\right)$ and energy product [7]. For example, the commercial Alnico 9 with a $5 \mathrm{wt} . \%$ Ti has a columnar grain structure, but the Alnico $8 \mathrm{H}$ with a $7.5 \mathrm{wt} . \% \mathrm{Ti}$ is randomly grained [4]. The columnar grain structure has been reported in $7.5 \% \mathrm{Ti}$ using the controlled cooling method with a speed of $5 \mathrm{~mm} / \mathrm{hr}$ [9], and in $8.2 \%$ Ti without disclosure of casting details [10]. No literature report can be found on successful casting of Ti composition higher than $8.2 \%$ with a columnar microstructure. This study explores the application of advanced directional solidification casting methods to $7.5 \%$ and higher $\mathrm{Ti}(9 \%$ and $12 \%$ ) compositions in order to form highly oriented columnar microstructures to improve the $\mathrm{B}_{\mathrm{r}}$ and energy products and maintain or improve the high $\mathrm{H}_{\mathrm{ci}}$ in these compositions.

\section{EXPERIMENTAL DETAILS}

Master ingots of three compositions of Alnico were cast by vacuum induction melting. Three casts were prepared in an ALD VIM-IC liquid metal cooled vacuum investment casting furnace using molds with cavity dimensions of $150 \times 38 \times 38 \mathrm{~mm}^{3}$. Liquid tin $(\mathrm{Sn})$ was used as the coolant medium. The alloy compositions, mold parameters, and casting conditions are listed in T ABLE I. 
The as-cast alloys were cut into $15 \times 10 \times 2 \mathrm{~mm}^{3}$ slices from the middle sections of the ingots. One slice for each composition was etched using Marble etchant (10 g CuSO4 in $50 \mathrm{ml} \mathrm{HCl}+50 \mathrm{ml} \mathrm{H} \mathrm{H}_{2} \mathrm{O}$ solution) for a few seconds to reveal dendritic structures evaluated using the LEO 1450VP SEM and KEYENCE VHX600 light microscope. Other slices were solution heat treated at different solutionization temperatures and time durations chosen as the ones to yield least secondary phase volume fractions based on the SEM data. The solutionized alloys were then cut into $\approx 4 \times 2 \times 2 \mathrm{~mm}^{3}$ parallelpipeds for thermomagnetic and draw cycle treatments in a magnetic field of $2.7 \mathrm{kOe}$ applied along the columnar grain direction at different temperatures and time durations optimized for different alloy compositions exhibiting the highest $\mathrm{H}_{\mathrm{ci}}$. In particular, because the spinodal decomposition temperature of each alloy composition was unknown, the magnetothermal treatments were carried out first at an estimated spinodal decomposition temperature $\left(\mathrm{T}_{1}\right)$ for 10 minutes, then at temperatures $20{ }^{\circ} \mathrm{C}$ higher $\left(\mathrm{T}_{2}\right)$ and lower $\left(\mathrm{T}_{3}\right)$ than $\mathrm{T}_{1}$. The $\mathrm{H}_{\mathrm{ci}}$ of the samples heat treated at these three temperatures were then measured. If the $\mathrm{H}_{\mathrm{ci}}$ of the sample heat treated at $\mathrm{T}_{2}$ was greater than that at $\mathrm{T}_{1}$, then the next heat treatment was set at a temperature $20{ }^{\circ} \mathrm{C}$ higher than $\mathrm{T}_{2}$. If the $\mathrm{H}_{\mathrm{ci}}$ of the sample heat treated at $T_{3}$ was greater than that at $T_{1}$, then the next heat treatment was set at a temperature $20{ }^{\circ} \mathrm{C}$ lower than $\mathrm{T}_{3}$. The $\mathrm{H}_{\mathrm{ci}}$ of each sample after every heat treatment was measured and compared, until a highest $\mathrm{H}_{\mathrm{ci}}$ was observed at a particular temperature $\left(\mathrm{T}_{\mathrm{n}}\right)$ for a specific alloy composition. Then the thermomagnetic treatments were carried out at temperatures $10{ }^{\circ} \mathrm{C}$ higher and lower than $\mathrm{T}_{\mathrm{n}}$. The $\mathrm{H}_{\mathrm{ci}}$ of the two samples were compared, and the temperature at which yielded the highest $\mathrm{H}_{\mathrm{ci}}$ was determined as the optimal thermomagnetic treatment temperature $\left(\mathrm{T}_{\mathrm{o}}\right)$ for the alloy composition. Then the same method was used to vary the heat treatment time between 1 and $120 \mathrm{~min}$ at $\mathrm{T}_{\mathrm{o}}$ for each alloy composition. The two-step draw cycle treatments were also optimized between 500 and $675{ }^{\circ} \mathrm{C}$ and between 6 and 48 hours in the same manner.

The magnetic properties of the heat treated samples were measured using a Quantum Design Physical Property Measurement System (PPMS) Model 6000 equipped with a vibrating sample magnetometer (VSM). The demagnetization factors were corrected using the equation derived in [11] by cutting samples 
into rectangular specimens and carefully measuring their dimensions. The appropriately-corrected openloop measurements were estimated to agree with closed-loop measurements to within $\pm 3 \%$ error [12].

Transmission electron microscopy (TEM) analysis was performed on transverse sections (with electron beam parallel to $\mathrm{H}$ direction) and on longitudinal orientation (with electron beam perpendicular to $\mathrm{H}$ direction) on a FEI Tecnai F20. TEM samples were prepared by mechanical wedge-polishing followed by a short time, low voltage Ar ion-milling with liquid nitrogen cold stage.

\section{RESULTS AND DISCUSSION}

The columnar grained microstructures are clearly evident in the optical images of the three alloys as shown Fig. 1.

For 1-D steady state directional solidification (DS), the liquid thermal gradient $\mathrm{G}_{\mathrm{L}}$ is expected to increase as the melt temperature $\mathrm{T}_{\text {melt }}$ decrease, based on the heat balance equation,

$$
G_{L}=\frac{k_{S} G_{S}-\rho_{m e l t}\left[H_{f}+C_{p, m e l t}\left(T_{m e l t}-T_{L}\right)\right] R}{k_{L}}
$$

where $\mathrm{G}_{\mathrm{L}}$ and $\mathrm{G}_{\mathrm{S}}$ are liquid and solid thermal gradients at the liquid-solid interface, $\mathrm{k}_{\mathrm{S}}$ and $\mathrm{k}_{\mathrm{L}}$ are liquid and solid metal thermal conductivities, $\rho_{\text {melt }}$ and $\mathrm{C}_{\mathrm{p} \text {,melt }}$ are melt density and specific heat, $\mathrm{T}_{\mathrm{L}}$ and $\mathrm{H}_{\mathrm{f}}$ are alloy liquidus temperature and latent heat, and $\mathrm{R}$ the liquid-solid interface growth rate [13]. At a given solidification rate, a higher $\mathrm{G}_{\mathrm{L}}$ enhances $\mathrm{DS}$ growth in the $\langle 001\rangle$ direction, which is coincident with Alnico easy direction for magnetization. The higher the $\mathrm{G}_{\mathrm{L}}$ is, the lower the misorientation and the stronger the $\langle 001\rangle$ texture is.

Replacing solid heat flux $\mathrm{k}_{S} \mathrm{G}_{\mathrm{S}}$ with DS heat extraction rate, $\mathrm{Q}_{\mathrm{DS}}$, Eq. (1) can be rewritten as Eq. (2),

$$
G_{L}=\frac{Q_{D S}-\rho_{m e l t}\left[H_{f}+C_{p, m e l t}\left(T_{m e l t}-T_{L}\right)\right] R}{k_{L}}
$$

For given casting design and withdraw rate $\mathrm{V}$ for a given alloy, $\mathrm{G}_{\mathrm{L}}$ increases as $\mathrm{Q}_{\mathrm{DS}}$ increases and $\mathrm{T}_{\text {melt }}$ decreases. If assuming steady state growth and constant thermal boundary conditions, QDs as a function of withdrawal length L, can then be expressed in Equations (3), (3a), and (4) 


$$
\begin{gathered}
Q_{D S}(L)=\frac{q_{z, 0}\left[T_{m}(L)-T_{\text {chill }}\right]}{\left[T_{S}-T_{\text {chill }}\right]}+\frac{2(W+D)}{W D} \int_{0}^{L=V t} q_{\text {ex }}(z) d z \\
=\frac{q_{z, 0}\left[T_{m}(L)-T_{\text {chill }}\right]}{\left[T_{S}-T_{\text {chill }}\right]}+\frac{1}{m_{c}} \int_{0}^{L=V t} q_{\text {ex }}(z) d z \\
q_{\text {ex }}=h_{\text {eff }}(L)\left[T_{m, \text { surf }}(L)-T_{a m b}\right]
\end{gathered}
$$

where $\mathrm{q}_{\mathrm{z}, 0}$ is initial heat flux through casting/mold support interface in withdrawal direction, $\mathrm{T}_{\mathrm{m}}(\mathrm{L})$ is casting temperature at mold support contact interface, $\mathrm{T}_{\text {chill }}$ is mold support temperature, $\mathrm{T}_{\mathrm{s}}$ is solidus temperature, $\mathrm{W}$ and $\mathrm{D}$ are width and thickness of the DS ingot, $\mathrm{q}_{\mathrm{ex}}$ is heat extraction rate normal to the vertical shell surface, $\mathrm{m}_{\mathrm{c}}$ is casting modulus (volume to surface ratio), $\mathrm{t}$ is withdrawal time, $\mathrm{h}_{\mathrm{eff}}$ is an effective heat transfer coefficient, $\mathrm{T}_{\mathrm{m} \text {,surf }}$ is metal surface temperature, and $\mathrm{T}_{\mathrm{amb}}$ is surrounding environment temperature. With certain approximations, $h_{\text {eff }}$ in Eq. (4) can be expressed in Equation (5) [14],

$$
\frac{1}{h_{\text {eff }}}=\frac{D}{2 k_{s}}+\frac{1}{h_{\text {gap }}}+\frac{t_{\text {shell }}}{k_{\text {shell }}}+\frac{1}{h_{\text {surf }}}
$$

where $k_{\text {shell }}$ and $t_{\text {shell }}$ are equivalent shell thermal conductivity and shell thickness, $h_{\text {gap }}$ is heat transfer coefficient at metal-shell gap depending on $\mathrm{T}_{\mathrm{m}}$, surf, and $\mathrm{h}_{\text {surf }}$ is heat transfer coefficient at shell surface

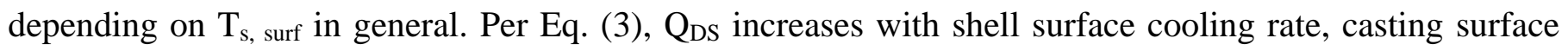
area, withdrawal rate and time, but decreases as casting volume increases. Substituting Eqs. (3), (4), and (5) into Eq. (2), an analytical description of $\mathrm{G}_{\mathrm{L}}$ dependency on casting parameters, cooling rate, part geometry and withdrawal length (or time) can be expressed in Equation (6),

$$
G_{L}=\frac{q_{z, 0}\left(\frac{T_{m}(L)-T_{\text {chill }}}{T_{S}-T_{\text {chill }}}\right)+\frac{1}{m_{c}} \int_{0}^{V t} q_{e x}(z) d z-\rho_{m e l t}\left[H_{f}+C_{p, \text { melt }}\left(T_{m e l t}-T_{L}\right)\right] R}{k_{L}}
$$

Assuming $\mathrm{R}=\mathrm{V}$, Equations (3) and (6) were solved numerically with iterations for Alnico bar castings of $38 \times 38 \mathrm{~mm}$ in cross section. The maximum horizontal shell surface heat extraction rate of the advanced SiC shell liquid metal cooling (LMC) process is then estimated as $230 \mathrm{KW} / \mathrm{m}^{2}$, compared to about $63 \mathrm{KW} / \mathrm{m}^{2}$ for the conventional Bridgman process, and $127 \mathrm{KW} / \mathrm{m}^{2}$ for the conventional LMC process.

Thin-walled SiC stucco-coated molds were developed and used for the 9\% $\mathrm{Ti}$ and 12\% Ti compositions [15], [16]. The measured thermal diffusivities and converted thermal conductivities show that the SiC shell 
has a $350 \%$ higher thermal conductivity than its alumina counterpart. The high thermal conductivity of the $\mathrm{SiC}$ shell mold and the low melt temperature $\left(\sim 100{ }^{\circ} \mathrm{C}\right.$ above their melting points determined from differential scanning calorimetry) in the casting method, enabled the formation of columnar structures in these high Ti compositions with a high withdraw rate, 152 and $203 \mathrm{~mm} / \mathrm{hr}$, much faster than the earlier report of $5 \mathrm{~mm} / \mathrm{hr}[9]$.

The composition heterogeneity as evident in Fig. 1 was mostly eliminated after solution heat treatment. The microstructures collected by SEM reveal a majority $\alpha$ phase with inclusions of secondary $\alpha_{\gamma}$ phase, as shown in Fig. 2 (a) to (c) as the light grey areas. The $\alpha_{\gamma}$ phase mostly segregated in the grain boundaries and it persists even in the subsequently magnetically annealed samples exhibiting the best $\mathrm{B}_{\mathrm{r}}$, $\mathrm{H}_{\mathrm{ci}}$, and $(\mathrm{BH})_{\max }$, as shown in Fig. 2 (d).

The best magnetic properties of each composition post magnetic field annealing are shown in TABLE I. The 7.5\% Ti composition exhibits high saturation magnetization $\left(\mathrm{M}_{\mathrm{s}}\right), \mathrm{B}_{\mathrm{r}}, \mathrm{H}_{\mathrm{ci}}$, and $(\mathrm{BH})_{\max }$, which compare favorably to typical properties of commercial grades high $(\mathrm{BH})_{\max }$ Alnico 9 and high $\mathrm{H}_{\mathrm{ci}}$ Alnico $8 \mathrm{H}$. The higher Ti composition in $9 \%$ Ti leads to a higher $\mathrm{H}_{\mathrm{ci}}$, but lower $\mathrm{M}_{\mathrm{s}}$ and $\mathrm{B}_{\mathrm{r}}$, causing an inferior $(\mathrm{BH})_{\max }$. In the $12 \%$ Ti composition, all magnetic properties are inferior.

TEM images shown in Fig. 3 were collected on the samples with their magnetic properties listed in TABLE I. The images demonstrate that the $\alpha$ phase is spinodally decomposed into a microstructure of FeCo-rich needles in a NiAl-rich matrix. In the 7.5\% Ti composition the diameter distribution of the FeCo needles is bimodal with the majority having diameters of approximately $50 \mathrm{~nm}$ and a small fraction having diameters of approximately $10 \mathrm{~nm}$, as shown in Fig. 3(b). The needles formed a mosaic pattern and a diamond shape viewed from the cross section as shown in Fig. 3(a) and (b), and were elongated along a $\langle 001\rangle$ crystal direction (parallel to the field used during magnetic annealing), as illustrated in Fig. 3(c) and (d). $\mathrm{Cu}$ precipitates were observed between the needles, as marked in the Fig. 3(b) and (d). TEM images collected on the transverse [Fig. 3 (a) and (b)] and longitudinal [Fig. 3(c) and (d)] to the orientations illustrate the strongly anisotropic spinodal structure of the $7.5 \%$ Ti composition, which explains the high $B_{r}$ 
observed in this composition.

Increasing $\mathrm{Ti}$ content to $9 \%$, the bimodal FeCo precipitates still form a mosaic pattern, but compared with the $7.5 \% \mathrm{Ti}$ composition, the small FeCo precipitates grow both in number and size, and the large FeCo precipitates grow slightly smaller, as shown in Fig. 3(e) to (h). The FeCo-rich phase volume fraction in $9 \%$ Ti qualitatively appears to be smaller than that in the $7.5 \%$ Ti. This may account for the $10 \%$ increase of $\mathrm{H}_{\mathrm{ci}}$ in the $9 \%$ Ti composition, considering $\mathrm{H}_{\mathrm{c}}(\mathrm{p})=\mathrm{H}_{\mathrm{c}}(0)(1-\mathrm{p})$, where $\mathrm{p}$ is the volume fraction of the FeCo-rich phase, and $\mathrm{H}_{\mathrm{c}}(0)$ is the coercivity of the single FeCo rich particle, $\mathrm{H}_{\mathrm{c}}(\mathrm{p})$ is the coercivity of the alloy [7]. Another distinct difference between the $9 \%$ and $7.5 \% \mathrm{Ti}$ compositions lies in their longitudinal morphologies. Instead of the majority of elongated FeCo needles are evenly and separately distributed in the NiAl matrix as shown in Fig. 3(c) and (d) in 7.5\% Ti, the FeCo needles are perpendicularly cross linked for 9\% Ti as shown in Fig. 3(g) and (h). Although the 9\% Ti was successfully cast to a columnar structure, unfortunately, the applied magnetic field fails to efficiently align the FeCo precipitates along the columnar grain direction. The nearly isotropic alignment of the FeCo precipitates are likely responsible for the nearly $50 \%$ drop of the $\mathrm{B}_{\mathrm{r}}$ of $9 \%$ Ti from the $7.5 \% \mathrm{Ti}$.

Further increasing the Ti content to $12 \%$, the spinodal microstructure shown in Fig. 3 (i) to (l) losses both mosaic pattern and anisotropy. Although the diameter and volume fraction of the FeCo precipitates reduce further, the cross linked FeCo needles may interact strongly with each other during the magnetization reversal, leading to a $35 \%$ drop of $\mathrm{H}_{\mathrm{ci}}$ from $7.5 \%$ Ti composition. The $\mathrm{B}_{\mathrm{r}}$ of $12 \%$ Ti reduces $26 \%$ further from $9 \%$ Ti due to the further reduced FeCo alignment anisotropy.

Regions of secondary phase precipitates and abnormal spinodal morphology were observed in TEM images of $7.5 \%, 9 \%$, and $12 \%$ Ti compositions. Fig. 4 shows representative images collected in the $7.5 \% \mathrm{Ti}$ composition. The interruption of the mosaic pattern and variation of the diameters and distances between the FeCo needles are evident in the vicinity of the secondary phase precipitates as shown in Fig. 4(b). The presence of these abnormalities, however, did not prevent the material from displaying superior magnetic properties most likely due to their low volume fraction. 


\section{CONClusion}

Advanced directional solidification methods were applied to Alnico with Ti concentrations of 7.5, 9, and 12 wt.\%. Low melt temperature and high thermal gradient achieved via thin-walled high thermal conductivity $\mathrm{SiC}$ shell mold enable the formation of highly oriented columnar grain structure in these high Ti compositions. Combined with appropriate magnetic field annealing, the $7.5 \%$ Ti composition measures $\mathrm{H}_{\mathrm{ci}}$ of $2.0 \mathrm{kOe}, \mathrm{B}_{\mathrm{r}}$ of $10.2 \mathrm{kG}$, and energy product of $10.9 \mathrm{MGOe}$, surpassing those of the commercial Alnico magnets. The unidirectionally elongated and distinctly separated FeCo needles and the uniform bimodal size distribution of these needles are responsible for its superior magnetic performance. The $9 \% \mathrm{Ti}$ composition exhibits a high $\mathrm{H}_{\mathrm{ci}}$ of $2.2 \mathrm{kOe}$, originated from the preservation of the bimodal mosaic microstructure. The $\mathrm{B}_{\mathrm{r}}$ of the $9 \% \mathrm{Ti}$ composition, however, drops almost $50 \%$ from the $7.5 \% \mathrm{Ti}$ composition because the alignment of the FeCo needles becomes more isotropic. The microstructure of the spinodally decomposed $12 \%$ Ti composition loses both the mosaic pattern and unidirectional elongation of the FeCo precipitates, yielding a 35\%, 60\%, and 87\% reduction of the $\mathrm{H}_{\mathrm{ci}}, \mathrm{B}_{\mathrm{r}}$, and $(\mathrm{BH})_{\max }$ from $7.5 \%$ Ti. The inability of the applied magnetic field to effectively align the FeCo precipitates in the $9 \%$ and $12 \% \mathrm{Ti}$ compositions is suggested to originate from a greater degree of separation of the spinodal decomposition and Curie temperatures in those compositions.

\section{ACKNOWLEDGMENT}

This work was supported in part by the U.S. Department of Energy under Grant DE-E0005573. [1]This report was prepared as an account of work sponsored by an agency of the U.S. Gov't. Neither the U.S. Gov’t nor any agency thereof, nor any of their employees, makes any warranty, express or implied, or assumes any legal liability or responsibility for the accuracy, completeness, or usefulness of any information, apparatus, product, or process disclosed, or represents that its use would not infringe privately owned rights. Reference herein to any specific commercial product, process, or service by trademark, manufacturer, or otherwise does not necessarily constitute or imply endorsement, recommendation or 
favoring by the U.S. Gov't of any agency thereof. The views and opinions of authors expressed herein do not necessarily state or reflect those of the U.S. Gov't or any agency thereof. Ames Laboratory is operated for the U.S. Department of Energy by Iowa State University under Contract No. DE-AC02-07CH11358. 


\begin{tabular}{||l|l|l|l|l||}
\hline \hline \multicolumn{2}{||l|}{ Sample ID } & $7.5 \% \mathrm{Ti}$ & $9 \% \mathrm{Ti}$ & $12 \% \mathrm{Ti}$ \\
\hline \multirow{4}{*}{ wt.\% } & $\mathrm{Al}$ & 7 & 8 & 7 \\
\cline { 2 - 5 } & $\mathrm{Ni}$ & 14 & 14 & 14 \\
\cline { 2 - 5 } & $\mathrm{Fe}$ & 29.5 & 26.6 & 25.5 \\
\cline { 2 - 5 } & $\mathrm{Co}$ & 39 & 39.4 & 39 \\
\cline { 2 - 5 } & $\mathrm{Cu}$ & 3 & 3 & 3 \\
\cline { 2 - 5 } & $\mathrm{Ti}$ & 7.5 & 9 & 12 \\
\hline Face coat stucco & Alumina & Alumina & Alumina \\
\hline Backup stucco & Alumina & Hi-K SiC & Hi-K SiC \\
\hline Shell thickness & $5 \mathrm{~mm}$ & $5 \mathrm{~mm}$ & $5 \mathrm{~mm}$ \\
\hline Melt temp. $\left({ }^{\circ} \mathrm{C}\right)$ & 1430 & 1430 & 1430 \\
\hline Withdraw rate $(\mathrm{mm} / \mathrm{hr})$ & 152 & 203 & 203 \\
\hline $\mathrm{M}_{\mathrm{s}}(\mathrm{kG})$ & 11.0 & 9.2 & 8.7 \\
\hline $\mathrm{B}_{\mathrm{r}}(\mathrm{kG})$ & 10.2 & 5.4 & 4.0 \\
\hline $\mathrm{H}_{\mathrm{ci}}(\mathrm{kOe})$ & 2.0 & 2.2 & 1.3 \\
\hline$(\mathrm{BH})_{\max }(\mathrm{MGOe})$ & 10.9 & 3.2 & 1.4 \\
\hline \hline
\end{tabular}

TABLE I. Compositions, mold and casting conditions, and magnetic properties of the alnico alloys processed by directional solidification methods and subsequent magnetic field annealing. 

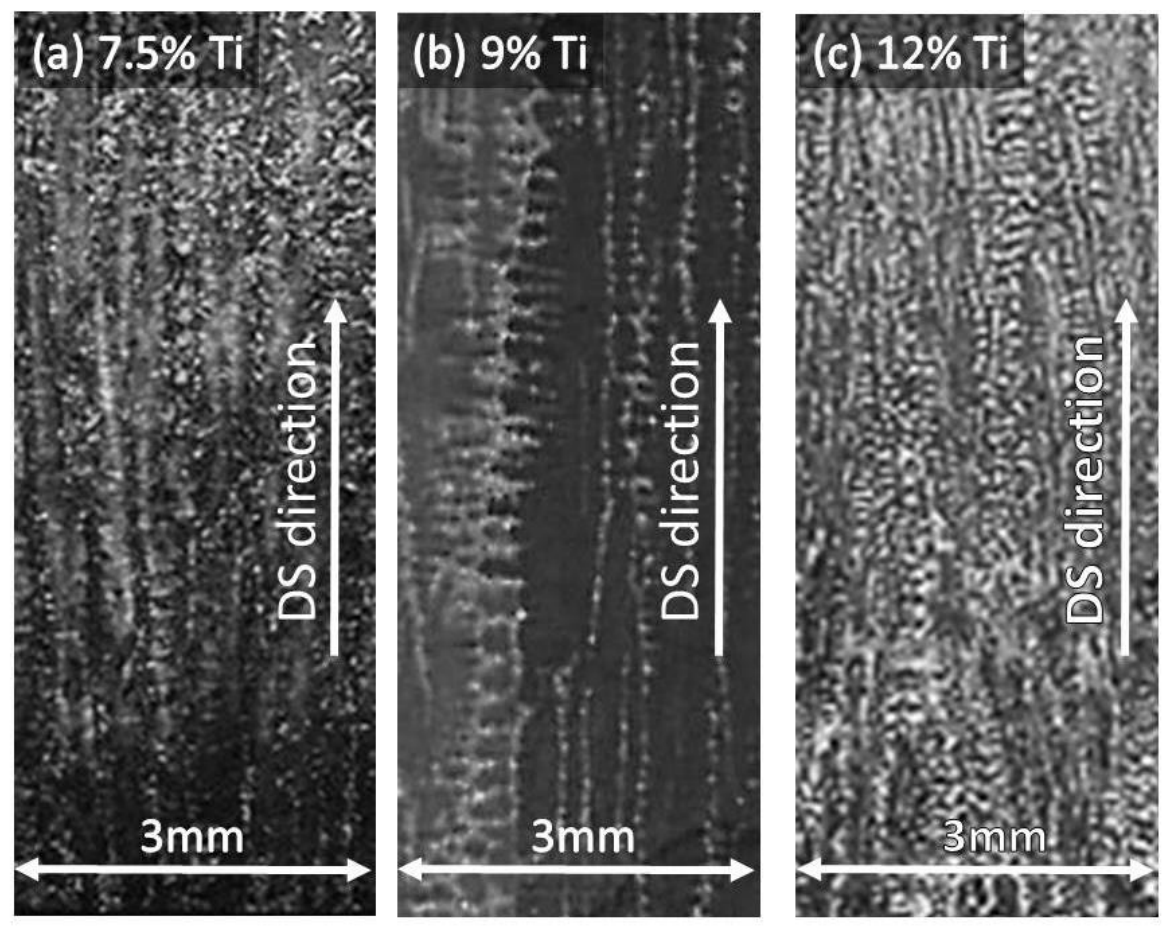

Fig. 1. Optical images of the as-cast Alnico with (a) 7.5\%, (b) 9\%, and (c) 12\% Ti compositions produced by advanced directional solidification methods. The vertical arrows mark the directional solidification direction. 


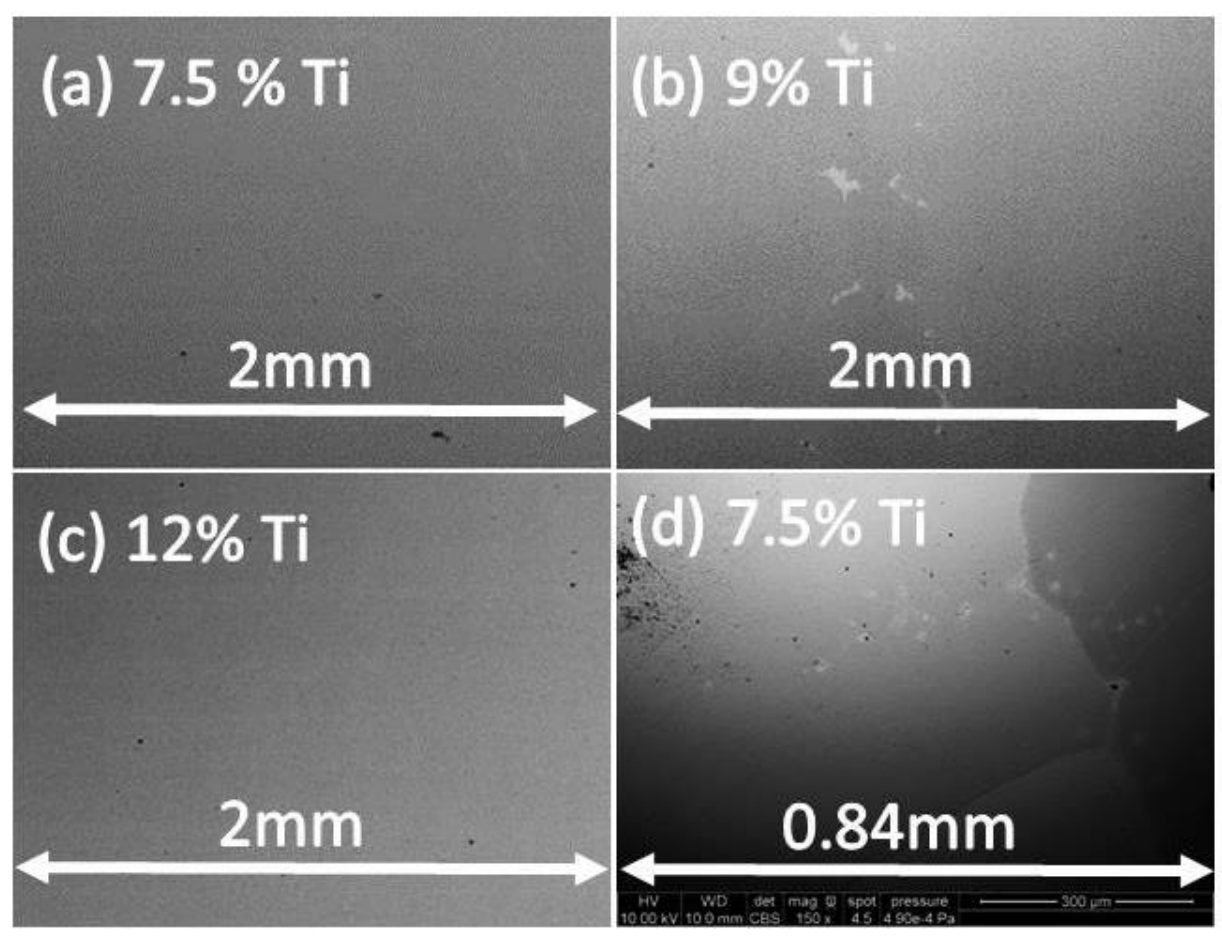

Fig. 2. Back scattered SEM images of solution heat treated (a) $7.5 \% \mathrm{Ti}$, (b) $9 \% \mathrm{Ti}$ and (c) $12 \% \mathrm{Ti}$ compositions, and (d) magnetic field annealed 7.5\% Ti composition produced by advanced directional solidification methods. 


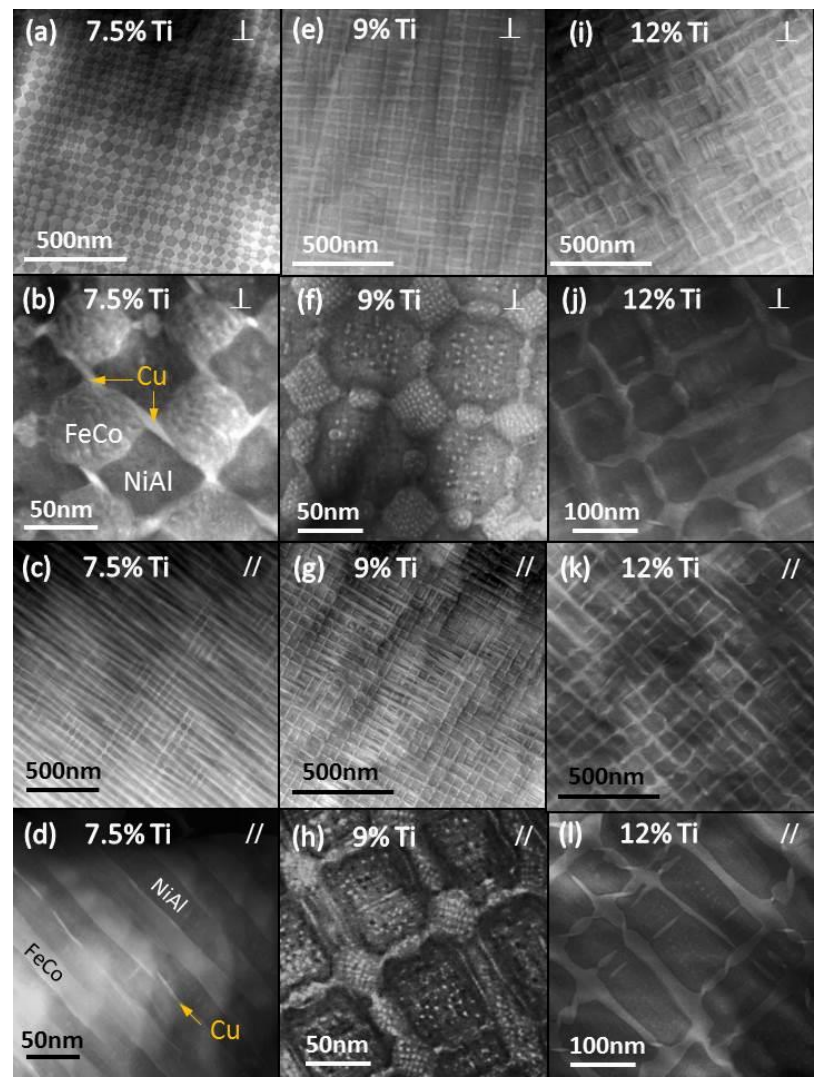

Fig. 3. TEM images of magnetic field annealed (a) to (d) $7.5 \% \mathrm{Ti}$, (e) to (h) $9 \% \mathrm{Ti}$, (i) to (l) $12 \% \mathrm{Ti}$ compositions produced by advanced directional solidification methods. The $\perp$ and // symbols on the top right corner of each image mark the orientation (transverse and longitudinal, respectively) to the magnetic field applied during annealing. 


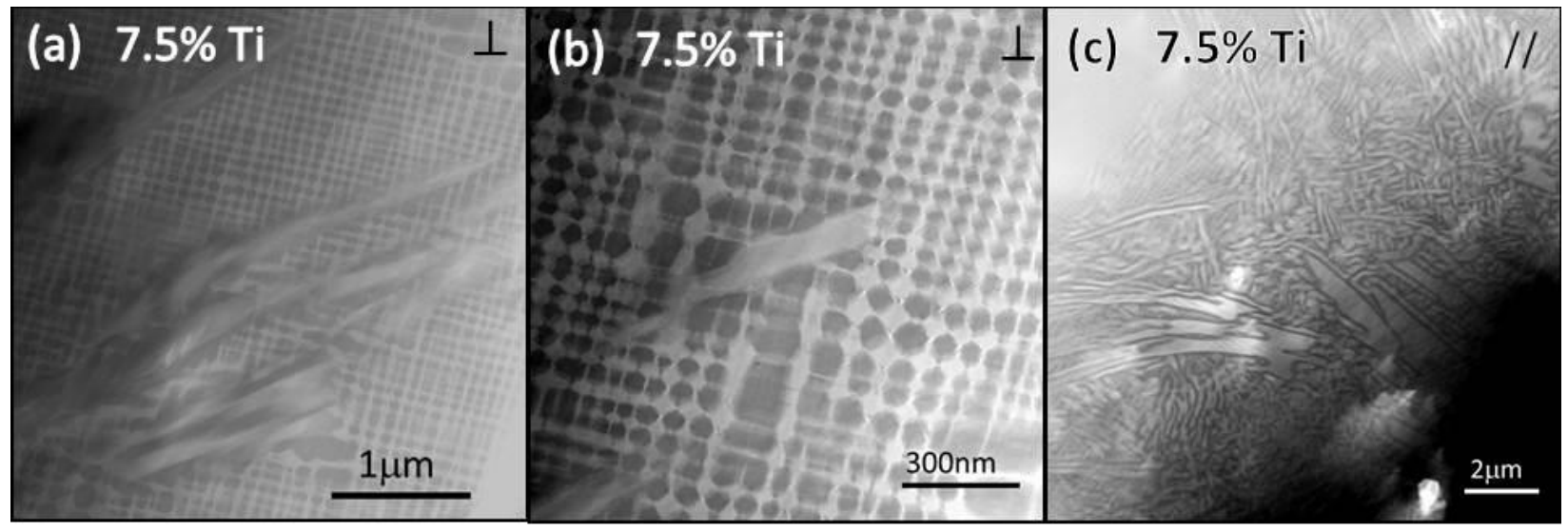

Fig. 4. TEM images of magnetic field annealed 7.5\% Ti composition produced by advanced directional solidification methods. The $\perp$ and // symbols on the top right corner of each image mark the transverse and longitudinal viewing orientations of the images, respectively. The transverse section at a) lower magnification and b) higher magnification show disruption of the normal mosaic pattern. 


\section{REFERENCES}

[1] I. E. Anderson, A. G. Kassen, E. M. H. White, L. Zhou, W. Tang, A. Palasyuk, K. W. Dennis, R. W. McCallum, and M. J. Kramer, "Novel pre-alloyed powder processing of modified alnico 8: Correlation of microstructure and magnetic properties," J. Appl. Phys.117, 17D138, Apr. 2015.

[2] T. Liu, W. Li, M. Zhu, Z. Guo, and Y. Li, "Effect of Co on the thermal stability and magnetic properties of AlNiCo 8 alloys," J. Appl. Phys. 115, 17A751, Mar. 2014.

[3] P. Lu, L. Zhou, M.K. Miller, and D. J. Smith, “Atomic-scale Chemical Imaging and Quantification of Metallic Alloy Structures by Energy-Dispersive X-ray Spectroscopy,” Scientific Reports 4, 3945, Feb. 2014.

[4] Lin Zhou, M.K. Miller, Ping Lu, Liqin Ke, R. Skomski, H. Dillon, Q. Xing, A. Palasyuk, M.R. McCartney, D.J. Smith, S. Constantinides, R.W. McCallum, I.E. Anderson, V. Antropv, M.J. Kramer, “Architecture and magnetism of alnico," Acta Materialia 74, pp. 224-233, Feb. 2014.

[5] Critical Materials Strategy, U.S. Department of Energy, Dec. 2011.

[6] R. Skomski, Y. Liu, J. E. Shield, G. C. Hadjipanayis, and D. J. Sellmyer, "Permanent magnetism of dense-packed nanostructures," J. Appl. Phys. 107, 09A739, May 2010.

[7] R. A. McCurrie, "The structure and properties of alnico permanent magnet alloys," Ferromagnetic Materials, Edited by E. P. Wohlfarth, Vol. 3, chapter 3, North-Holland Publishing Company, 1982.

[8] "Standard specifications for Permanent Magnet Materials," MMPA STANDARD, No. 0100-00, Magnetic Materials Producers Association, Chicago, IL. http://www.intemag.com/pdf/MMPA010000.pdf, pp.7, TABLE II-1.

[9] A. Hoffmann and H. Stablein, "Investigations of high-coercivity alnico alloys," IEEE Trans. Magn. MAG-6 (2), pp. 225-230, 1970.

[10] Y.L. Sun, J.T. Zhao, Z. Liu, W.X. Xia, S.M. Zhu, D. Lee, A.R.Yan, "The phase and microstructure analysis of Alnico magnets with high coercivity", J. Magn. Magn. Mater. Volume 379, pp. 58-62, Apr. 2015. 
[11] A. Aharoni, "Demagnetizing factors for rectangular ferromagnetic prisms,” J. Appl. Phys. Vol. 83, pp. 3432, 1998.

[12]B. C. Dodrill, B. J. Kelley, "Measurements with a VSM: Permanent Magnet Materials”, Application Note, Lakeshore Cryotronics, Inc., http://www.lakeshore.com/Documents/Permanent\%20Magnet\%20Paper.pdf

[13] W. Kurz, D. J. Fisher, Fundamentals of Solidification, Trans Tech Publications, 1986

[14]M. Konter, E. Kats, and N. Hofmann, "A Novel casting process for single crystal gas turbine components," Superalloys 2000, pp.189-200, Edited by T.M. Pollock, R.D. Kissinger, R.R. Bowman, K.A. Green, M. McLean, S. Olson, and J.J. Schirra, TMS 2000.

[15]Q. Zhao, F. Johnson, S. F. Rutkowski, M. Zou, W. Zhang, "Methods for Directional Solidificational Casting” United States Patent Application Pub. No. US2015/0231696A1, Aug. 2015.

[16] Q. Zhao, F. Johnson, S. F. Rutkowski, W. Zhang, M. Zou, "High Thermal Conductivity Shell molds”, United States Patent Application Pub. No. US2015/0144287A1, May. 2015. 